\title{
A calculation method for friction coefficient and meshing efficiency of plastic line gear pair under dry friction conditions
}

\author{
Yangzhi CHEN*, Yifan LIN \\ School of Mechanical and Automotive Engineering, South China University of Technology, Guangzhou 510640, China \\ Received: 12 December 2019 / Revised: 13 May 2020 / Accepted: 28 June 2020 \\ (C) The author(s) 2020 .
}

\begin{abstract}
A calculation method for the friction coefficient and meshing efficiency of plastic line gear (LG) pair under dry friction conditions was studied theoretically and experimentally, taking a polyoxymethylene parallel line gear pair (POM PLGP) as an example. Firstly, the geometric and mechanical models of PLGP were built by considering the effects of misalignment and loaded deformation under the actual operating condition. Then, the friction coefficient of POM specimens was obtained via the ball-on-disk experiment, of which the value varies between 0.35 and 0.45 under the experimental conditions. The calculation formula for the friction coefficient of POM LG pair was obtained by fitting the friction coefficient of the POM specimens, and the meshing efficiency of POM LG pair was calculated based on the calculation formula for friction coefficient and the meshing efficiency calculation approach. Finally, the meshing efficiency of POM PLGP specimens was measured using a homemade gear meshing efficiency test rig. The experimental results validated the feasibility of the proposed calculation method for the friction coefficient and meshing efficiency of the plastic LG pair. This study provides a method for the calculation of the friction coefficient and meshing efficiency of plastic gear pairs under dry friction conditions. It also provides the basis for the wear calculation of plastic LG pair under dry friction conditions.
\end{abstract}

Keywords: line gear (LG) pair; friction coefficient; meshing efficiency; dry friction; polyoxymethylene (POM)

\section{Introduction}

The advantages of plastic gears, such as lightweight, low noise, self-lubrication, and low cost, have led to their wide use in gearing systems applied under conditions of dry friction, low rotational speed, and light load, such as measuring instruments, food machinery, and mobile communication equipment [1-4]. The remote control unit (RCU) is the core equipment of a base station antenna, which can realize the tilt angle adjustment through a gear transmission system. Polyoxymethylene (POM) is free from electromagnetic interference and has the advantages of low hygroscopicity, high strength, and good wear resistance [5-7]. Thus, POM gear pairs are commonly used in RCU. However, relative sliding between meshing surfaces occurs throughout the meshing process (except for the pitch point) of commonly used POM gear pairs, such as spur gear, helical gear, and worm gear pairs, which results in low meshing efficiency and restricts the application of POM gear pairs under dry friction conditions $[3$, $8,9]$.

Line gear (LG), a novel gear mechanism invented based on the space curve meshing theory proposed by Chen et al. [10,11], achieves transmission through the continuous point-contact meshing of a pair of space conjugate curves called driving and driven

* Corresponding author: Yangzhi CHEN, E-mail: meyzchen@scut.edu.cn 


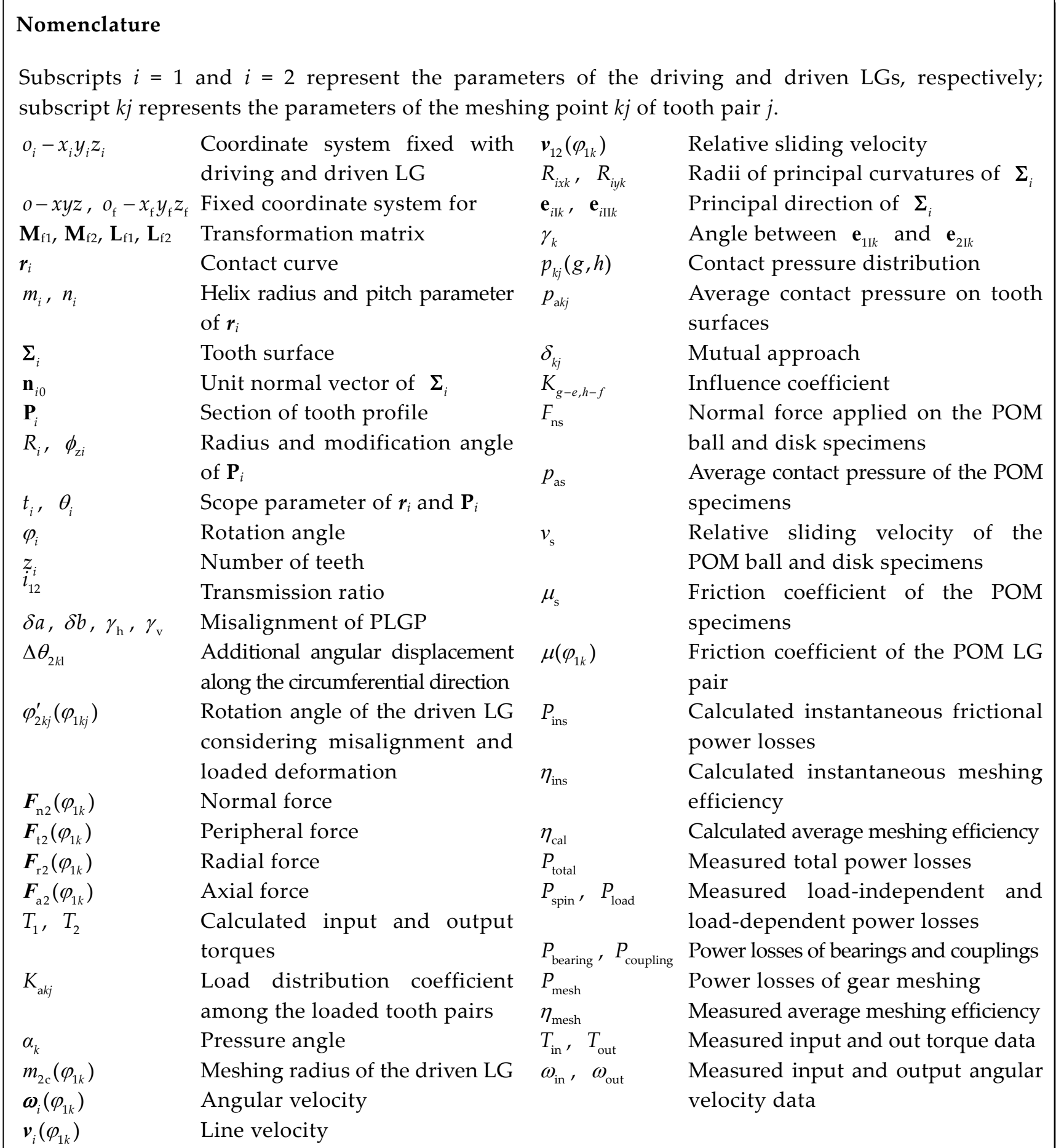

contact curves. Relative sliding during the meshing process can be eliminated by the innovative design of the LG pair, i.e., by selecting the parameters of driving and driven contact curves the sliding rates of the LG pair can be made equal to zero [12]. For example, when a cylindrical helix is selected as the driving contact curve of a parallel LG pair (PLGP), the sliding rates can be equal to zero throughout the meshing process [13]. This indicates that high meshing efficiency can be achieved even under 
dry friction conditions. Therefore, PLGP is a good choice for gearing applications under dry friction conditions. However, misalignment and loaded deformation under the actual operating condition could change the actual meshing positions of the LG pair. This leads to relative sliding between the meshing surfaces, which influences the meshing efficiency. Thus, it is necessary to study the meshing efficiency of LG pairs under the actual operating condition.

Frictional loss caused by relative sliding between meshing surfaces is the main reason for low meshing efficiency under dry friction conditions. It is a function of load, relative sliding velocity, and friction coefficient of the gear pair [9, 14, 15]. Thus, determining the friction coefficient of the gear pair is the key to studying the meshing efficiency. Larson and Timpe [16], Ziemianski and Capanidis [17], and Ginzburg et al. [18] measured the friction coefficient of POM against steel under various loads, relative sliding velocities, and lubrication conditions, however, they did not derive any calculation formulas for the friction coefficient. Xiong et al. [19] conducted a pin-ondisk experiment and obtained a calculation formula for the friction coefficient of POM under dry friction conditions. However, the formula is not associated with the operating conditions of any gear pair. Besides, the face-contact model of the pin and disk specimens is completely different from the point-contact model of the LG pair. Thus, the formula based on the pin-on-disk experiment is unsuitable to be used to calculate the friction coefficient of the LG pair. Miler et al. [20] proposed a calculation formula for the friction coefficient of the POM spur gear pair. However, this formula is only valid for POM spur gear with polytetrafluoroethylene (PTFE) lubricant and had not been validated by the gear transmission experiment. In short, we have not found any calculation methods or formulas for the friction coefficient of plastic gear pairs under dry friction conditions.

There are three existing methods to determine the friction coefficient of the gear pair. The first method assumes a constant friction coefficient throughout the meshing process $[21,22]$. However, the friction coefficient varies with changes in operating conditions. The second method determines the friction coefficient using the models based on friction mechanism and lubrication theory. $\mathrm{Xu}$ and Kahraman [14, 15] proposed an effective method for calculating the friction coefficient based on the elastohydrodynamic lubrication (EHL) model when studying the meshing efficiency of steel spur and helical gear pairs. The third method determines the friction coefficient by the empirical formulas based on the measured friction coefficient data of the materials of the gear pair. Marjanovic et al. [23] measured the friction coefficient of steel specimens and established a calculation formula for the friction coefficient of steel spur gear pairs under oil lubrication. For the third method, a certain number of friction coefficient tests are needed, and the types and conditions of the tests can be selected according to the types, materials, and operating conditions of the gear pairs. Thus, the third method can be applied to determine the friction coefficient of plastic gear pairs under dry friction conditions.

In this paper, the friction coefficients of POM specimens were measured through the ball-ondisk experiment by considering the point-contact model of the LG pair, and the calculation formula for the friction coefficient of the POM LG pair is obtained. On this basis, the calculation formula for the meshing efficiency of the POM LG pair was derived. The feasibility of the calculation formulas for the friction coefficient and meshing efficiency of the POM LG pair was then validated by comparing the calculated and measured meshing efficiency values of the POM LG pair specimens.

\section{Geometric and mechanical models of PLGP}

Meshing efficiency is a function of load, relative sliding velocity, and friction coefficient. The friction coefficient is influenced by the contact pressure and relative sliding velocity. In this section, the normal force, contact pressure, and relative sliding velocity are deduced based on the geometric and mechanical models of PLGP under the actual operating condition. 


\subsection{Geometric model of PLGP considering misa- lignment under the actual operating condition}

As shown in Fig. 1, $0-x y z$ and $o_{\mathrm{f}}-x_{\mathrm{f}} y_{\mathrm{f}} z_{\mathrm{f}}$ are fixed coordinate systems for the driving and driven LGs, respectively. Coordinate systems $o_{1}-x_{1} y_{1} z_{1}$ and $o_{2}-x_{2} y_{2} z_{2}$ are fixed with the driving and driven LGs, respectively. Axis $z_{1}(z)$ and $z_{2}\left(z_{\mathrm{f}}\right)$ with a distance of $a$ coincide with the rotation axes of the driving and driven LGs, respectively. If the driving contact curve $\boldsymbol{r}_{1}$ is a right-hand cylindrical helix, then the driven contact curve $\boldsymbol{r}_{2}$ is a lefthand one according to the space curve meshing theory $[10,11]$. In the normal plane of an arbitrary point on $\boldsymbol{r}_{i}$, an $\operatorname{arc} \mathbf{P}_{i}$ is chosen as the generatrix

and made to sweep along $\boldsymbol{r}_{i}$. The tooth surface $\boldsymbol{\Sigma}_{i}$ is formed, where the subscripts $i$ equal to 1 or 2 , representing the parameters of the driving and driven LGs, respectively. $\boldsymbol{r}_{1}$ and $\boldsymbol{r}_{2}$ in $o_{1}-x_{1} y_{1} z_{1}$ and $o_{2}-x_{2} y_{2} z_{2}$ are expressed as Eqs. (1) and (2), and $\Sigma_{1}$ and $\Sigma_{2}$ are expressed as Eqs. (3) and (4), respectively.

$$
\begin{aligned}
\boldsymbol{r}_{1}^{(1)}\left(t_{1}\right) & =\left(\begin{array}{l}
m_{1} \cos \left(t_{1}\right) \\
m_{1} \sin \left(t_{1}\right) \\
n_{1}\left(t_{1}+\pi\right)
\end{array}\right) \quad\left(t_{1 \mathrm{~s}} \leqslant t_{1} \leqslant t_{1 \mathrm{e}}\right) \\
\boldsymbol{r}_{2}^{(2)}\left(t_{2}\right) & =\left(\begin{array}{l}
m_{2} \cos \left(t_{2}\right) \\
m_{2} \sin \left(t_{2}\right) \\
n_{2} t_{2}
\end{array}\right)\left(\frac{t_{1 \mathrm{~s}}}{i_{12}} \leqslant t_{2} \leqslant \frac{t_{1 \mathrm{e}}}{i_{12}}\right)
\end{aligned}
$$

where $m_{i}$ is the helix radius of $\boldsymbol{r}_{i}, m_{1}>0$, and $m_{2}>$ $0 ; n_{i}$ the screw parameter of $\boldsymbol{r}_{i}, n_{1}>0$, and $n_{2}<0$. $i_{12}$ is the transmission ratio, and $m_{2}=i_{12} m_{1}, n_{2}=$ $-i_{12} n_{1} . t_{i}$ is the parameter indicating the scope of $\boldsymbol{r}_{i}$. Driving and driven contact curves begin to mesh when $t_{i}$ equals to $t_{i s}$, and begin to separate when $t_{i}$ equals to $t_{i \mathrm{e}} \cdot \theta_{i}$ is the parameter indicating the scope of $\mathbf{P}_{i} . R_{i}$ is the radius of $\mathbf{P}_{i} . \phi_{z i}$ is the modification angle of the tooth profile.

Misalignments under the actual operating condition may change the actual meshing positions of the LG pair, which may influence the normal force, contact pressure, and relative sliding velocity, followed by the friction coefficient and meshing efficiency. As shown in Fig. 2, misalignments of the PLGP are classified as follows: center distance deviation, i.e., an extra displacement $\delta a$ in the

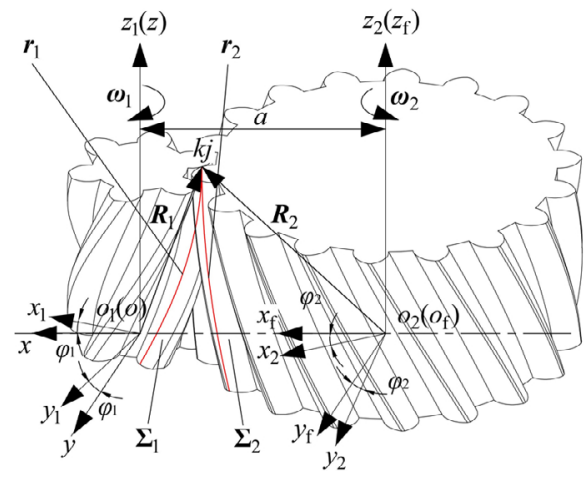

Fig. 1 Geometric model of PLGP. 


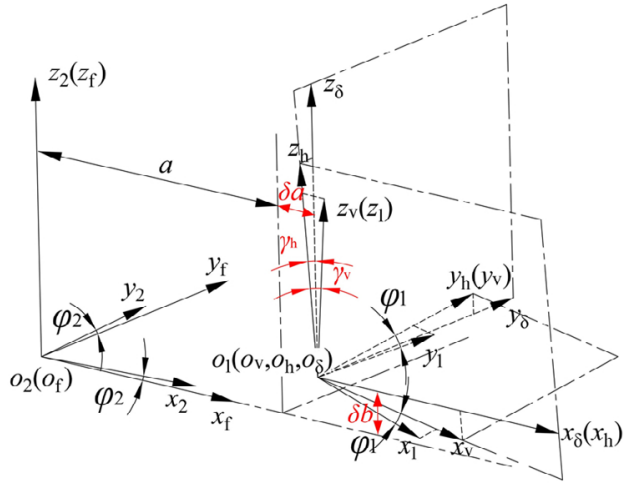

Fig. 2 Misalignments of PLGP. direction of axis $x_{\mathrm{f}}$; axial deviation, i.e., an extra displacement $\delta b$ in the direction of $z_{\mathrm{f}}$; and parallel deviation of the axes, i.e., the angle $\gamma_{\mathrm{h}}$ between the projections of the axis $z_{1}$ and $z_{2}$ in the plane $y_{\mathrm{f}} \mathrm{o}_{\mathrm{f}} z_{\mathrm{f}}$, and the angle $\gamma_{\mathrm{v}}$ between the projections of the axis $z_{1}$ and $z_{2}$ in the plane $x_{\mathrm{f}} \mathrm{o}_{\mathrm{f}} z_{\mathrm{f}}$. The values of $\delta a, \delta b, \gamma_{\mathrm{h}}$, and $\gamma_{\mathrm{v}}$ shown in Fig. 2 are all positive.

Transformation matrix $\mathbf{M}_{\mathrm{f} 1}$ from $o_{1}-x_{1} y_{1} z_{1}$ to $o_{\mathrm{f}}-x_{\mathrm{f}} y_{\mathrm{f}} z_{\mathrm{f}}$, and $\mathbf{M}_{\mathrm{f} 2}$ from $o_{2}-x_{2} y_{2} z_{2}$ to $o_{\mathrm{f}}-x_{\mathrm{f}} y_{\mathrm{f}} z_{\mathrm{f}}$ are presented as Eqs. (5) and (6), respectively.

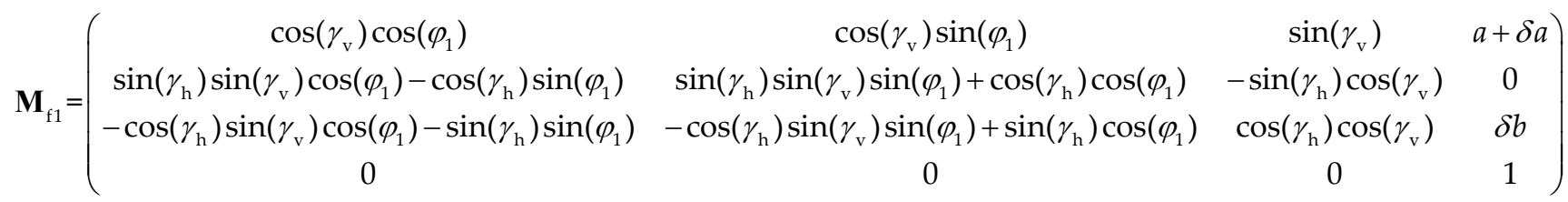

$$
\mathbf{M}_{\mathrm{f} 2}=\left(\begin{array}{cccc}
\cos \left(\varphi_{2}\right) & -\sin \left(\varphi_{2}\right) & 0 & 0 \\
\sin \left(\varphi_{2}\right) & \cos \left(\varphi_{2}\right) & 0 & 0 \\
0 & 0 & 1 & 0 \\
0 & 0 & 0 & 1
\end{array}\right)
$$

where $\varphi_{1}$ and $\varphi_{2}$ are the rotation angles of the driving and driven LGs, respectively.

The tooth surface expressions and tooth surface normal vector expressions in $o_{\mathrm{f}}-x_{\mathrm{f}} y_{\mathrm{f}} z_{\mathrm{f}}$ are presented as Eqs. (7) and (8); $\mathbf{L}_{\mathrm{f} 1}$ and $\mathbf{L}_{\mathrm{f} 2}$ are the third-order submatrices of $\mathbf{M}_{\mathrm{f} 1}$ and $\mathbf{M}_{\mathrm{f} 2}$, respectively. The direction from the tooth entity to the outside of the tooth is the positive direction of $\mathbf{n}_{10}$, and the direction from the outside of the tooth to the tooth entity is the positive direction of $\mathbf{n}_{20}$.

$$
\begin{aligned}
& \left\{\begin{array}{l}
\Sigma_{1}^{(\mathrm{f})}\left(t_{1}, \theta_{1}, \varphi_{1}\right)=\mathbf{M}_{\mathrm{f} 1}\left(\varphi_{1}\right) \cdot \Sigma_{1}^{(1)}\left(t_{1}, \theta_{1}\right) \\
\Sigma_{2}^{(\mathrm{f})}\left(t_{2}, \theta_{2}, \varphi_{2}\right)=\mathbf{M}_{\mathrm{f} 2}\left(\varphi_{2}\right) \cdot \Sigma_{2}^{(2)}\left(t_{2}, \theta_{2}\right)
\end{array}\right. \\
& \left\{\begin{array}{l}
\mathbf{n}_{10}^{(\mathrm{f})}\left(t_{1}, \theta_{1}, \varphi_{1}\right)=\mathbf{L}_{\mathrm{f} 1}\left(\varphi_{1}\right) \cdot \mathbf{n}_{10}^{(1)}\left(t_{1}, \theta_{1}\right) \\
\mathbf{n}_{20}^{(\mathrm{f})}\left(t_{2}, \theta_{2}, \varphi_{2}\right)=\mathbf{L}_{\mathrm{f} 2}\left(\varphi_{2}\right) \cdot \mathbf{n}_{20}^{(2)}\left(t_{2}, \theta_{2}\right)
\end{array}\right.
\end{aligned}
$$

The condition of continuous tangential contact between the tooth surfaces at the meshing points is presented by Eq. (9) [24].

$$
\left\{\begin{array}{l}
\Sigma_{1}^{(\mathrm{f})}\left(t_{1}, \theta_{1}, \varphi_{1}\right)=\Sigma_{2}^{(\mathrm{f})}\left(t_{2}, \theta_{2}, \varphi_{2}\right) \\
\mathbf{n}_{10}^{(\mathrm{f})}\left(t_{1}, \theta_{1}, \varphi_{1}\right)=\mathbf{n}_{20}^{(\mathrm{f})}\left(t_{2}, \theta_{2}, \varphi_{2}\right)
\end{array}\right.
$$

A meshing period from meshing start to meshing end of tooth pair $j$ is divided evenly into $K$ meshing positions, and the rotation angle of the driving LG is given as $\varphi_{1 k j}(k=1, \ldots, K)$. By substituting $\varphi_{1 k j}$ into Eq. (9), the other five unknown parameters $t_{1 k j}\left(\varphi_{1 k j}\right)$, $t_{2 k j}\left(\varphi_{1 k j}\right), \theta_{1 k j}\left(\varphi_{1 k j}\right), \theta_{2 k j}\left(\varphi_{1 k j}\right)$, and $\varphi_{2 k j}\left(\varphi_{1 k j}\right)$ are calculated. The coordinates of the meshing point $k j$ on $\Sigma_{1}$ and $\Sigma_{2}$ are $\left(t_{1 k j}\left(\varphi_{1 k j}\right), \theta_{1 k j}\left(\varphi_{1 k j}\right), \varphi_{1 k j}\right)$ and $\left(t_{2 k j}\left(\varphi_{1 k j}\right)\right.$, $\left.\theta_{2 k j}\left(\varphi_{1 k j}\right), \varphi_{2 k j}\left(\varphi_{1 k j}\right)\right)$, respectively.

\subsection{Normal force and contact pressure on the tooth surfaces}

In this section, the normal force on the tooth surfaces is deduced first, followed by the contact pressure on the tooth surfaces according to the radii of principal curvatures and the angle between the principal directions at the meshing points.

\subsubsection{Normal force on the tooth surfaces}

Taking the driven LG, the normal force $\boldsymbol{F}_{\mathrm{n} 2}\left(\varphi_{1 k j}\right)$ is applied perpendicularly on the tooth surface $\Sigma_{2}$ at the meshing point $k j$ of the tooth pair $j$, as shown in Fig. 3. $\boldsymbol{F}_{\mathrm{n} 2}\left(\varphi_{1 k j}\right)$ is divided into the peripheral force $\boldsymbol{F}_{\mathrm{t} 2}\left(\varphi_{1 k j}\right)$, radial force $\boldsymbol{F}_{\mathrm{r} 2}\left(\varphi_{1 k j}\right)$, and axial force $\boldsymbol{F}_{\mathrm{a} 2}\left(\varphi_{1 k j}\right)$. The contact ratio of an LG pair is usually greater than 1, i.e., the number of tooth pairs meshing simultaneously is at least one during the meshing process. Thus, the total torque on the driven LG is the sum of torques on the tooth pairs meshing simultaneously:

$$
\sum_{j=1}^{J} F_{\mathrm{t} 2}\left(\varphi_{1 k j}\right) \cdot m_{2 \mathrm{c}}\left(\varphi_{1 k j}\right)=T_{2}
$$




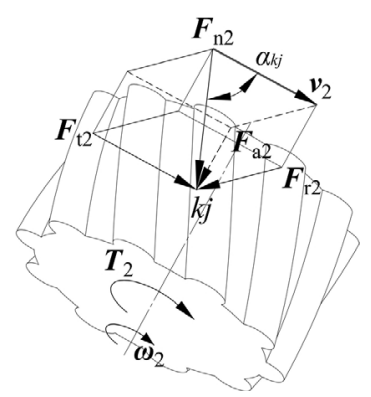

Fig. 3 Forces applied at the point $k j$ of the tooth pair $j$ of the driven LG.

where $J$ is the number of the tooth pairs meshing simultaneously; $F_{\mathrm{t} 2}\left(\varphi_{1 k j}\right)$ is the magnitude of $\boldsymbol{F}_{\mathrm{t} 2}\left(\varphi_{1 k j}\right)$ at the point $k j$ of tooth pair $j ; m_{2 \mathrm{c}}\left(\varphi_{1 k j}\right)$ is the meshing radius at the point $k j$ of tooth pair $j$ of the driven LG; and $T_{2}$ is the output torque.

The load distribution coefficient among the loaded tooth pairs $K_{a k j}$ is introduced to simplify the calculation of the normal force, where $K_{\mathrm{akj}}$ is equal to 1 in the case of single-tooth meshing, 0.5 in the case of double-tooth meshing, and so on. Then, the magnitude of $\boldsymbol{F}_{\mathrm{n} 2}\left(\varphi_{1 k j}\right)$ is presented as Eq. (11).

$$
F_{\mathrm{n} 2}\left(\varphi_{1 k j}\right)=\frac{K_{\mathrm{akj}} T_{2}}{m_{2 \mathrm{c}}\left(\varphi_{1 k j}\right) \cdot \cos \alpha_{k j}}
$$

where $F_{\mathrm{n} 2}\left(\varphi_{1 k j}\right)$ is the magnitude of $\boldsymbol{F}_{\mathrm{n} 2}\left(\varphi_{1 k j}\right)$ at the point $k j$ of tooth pair $j ; \alpha_{k j}$ is the pressure angle at the point $k j$ of tooth pair $j$, i.e., the angle between $\boldsymbol{F}_{\mathrm{n} 2}\left(\varphi_{1 k j}\right)$ and the line velocity $\boldsymbol{v}_{2}\left(\varphi_{1 k j}\right)$ of the driven LG, and $\cos \alpha_{k j}=\left(\boldsymbol{F}_{\mathrm{n} 2}\left(\varphi_{1 k j}\right) \cdot \boldsymbol{v}_{2}\left(\varphi_{1 k j}\right)\right) /$ $\left(\left|\boldsymbol{F}_{\mathrm{n} 2}\left(\varphi_{1 k j}\right)\right| \cdot\left|\boldsymbol{v}_{2}\left(\varphi_{1 k j}\right)\right|\right)$.

\subsubsection{Contact pressure on the tooth surfaces}

Large contact pressure may occur at the meshing points due to the point-contact model of the LG pair. Contact deformation is the main type of loaded deformation. Meshing surfaces of tooth pair $j$ are regarded as two elastic bodies that are initially in contact at the meshing point $k j$, as indicated by the solid curves in Fig. 4 . When the

$$
\left\{\begin{array}{l}
A+B=\frac{1}{2}\left(\frac{1}{R_{1 x k j}}+\frac{1}{R_{1 y k j}}+\frac{1}{R_{2 x k j}}+\frac{1}{R_{2 y k j}}\right) \\
B-A=\frac{1}{2} \sqrt{\left(\frac{1}{R_{1 x k j}}-\frac{1}{R_{1 y k j}}\right)^{2}+\left(\frac{1}{R_{2 x k j}}-\frac{1}{R_{2 y k j}}\right)^{2}+2\left(\frac{1}{R_{1 x k j}}-\frac{1}{R_{1 y k j}}\right)\left(\frac{1}{R_{2 x k j}}-\frac{1}{R_{2 y k j}}\right) \cos 2 \gamma_{k j}}
\end{array}\right.
$$

where $R_{1 x k j}$ and $R_{1 y k j}$ are the radii of principal curvatures at the point $k j$ on the tooth surface $\Sigma_{1}$.

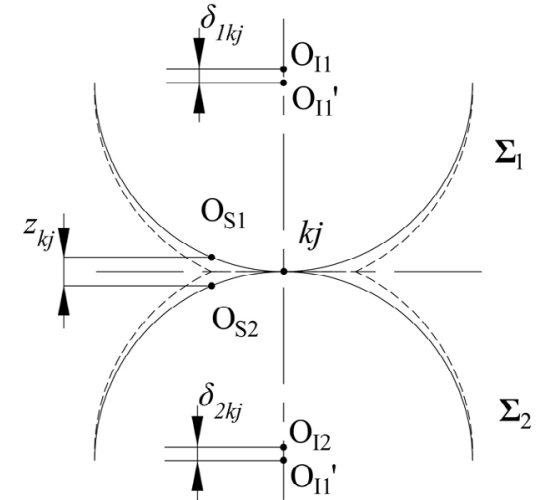

Fig. 4 Contact between the tooth surfaces at the point $k j$.

tooth pair is loaded, two opposing points $\mathrm{O}_{\mathrm{S} 1}$ and $\mathrm{O}_{\mathrm{S} 2}$, on the tooth surfaces $\Sigma_{1}$ and $\Sigma_{2}$, with an initial separation of $z_{k j}$, are brought into contact, as indicated by the dashed curves in Fig. 4 . Meanwhile, two opposing points $\mathrm{O}_{\mathrm{I} 1}$ and $\mathrm{O}_{\mathrm{I} 2}$, inside the teeth, approach point $k j$ with distances of $\delta_{1 k j}$ and $\delta_{2 k j}$, respectively.

The influence coefficient method is an efficient method to solve for the contact pressure and deformation [25]. A calculation domain containing the actual contact region is discretized into $N_{x} \times N_{y}$ elements denoted as $(g, h)\left(g=1,2, \ldots, N_{x}, h=1,2, \ldots\right.$, $N_{y}$ ). Equation (12) is satisfied within the calculation domain.

$$
\left\{\begin{array}{l}
\sum_{g=1}^{N_{x}} \sum_{h=1}^{N_{y}} p_{k j}(g, h) \cdot \Delta x \cdot \Delta y=F_{\mathrm{n} 2}\left(\varphi_{1 k j}\right) \\
u_{k j}=\delta_{k j}-z_{k j}, p_{k j}(g, h)>0 \\
u_{k j}>\delta_{k j}-z_{k j}, p_{k j}(g, h)=0
\end{array}\right.
$$

where $p_{k j}(g, h)$ is the contact pressure on the element $(g, h) ; \Delta x \cdot \Delta y$ is the area of a single element; $u_{k j}=u_{1 k j}+u_{2 k j}$ is the normal displacement of the tooth surfaces; $\delta_{k j}=\delta_{1 k j}+\delta_{2 k j}$ is the mutual approach of the teeth; and $z_{k j}=A x^{2}+B y^{2}$ represents the initial separation between the tooth surfaces, where $A$ and $B$ are obtained from Eq. (13) [26]. 
and $\mathbf{e}_{2 \mathrm{I} k i}$ corresponding to $R_{1 x k j}$ and $R_{2 x k j}$, respectively.

According to the influence coefficient method, the total deformation of the element $(g, h)$ is shown as Eq. (14), which is a superposition of deformation caused by contact pressure within the whole contact region.

$$
u_{k j}(g, h)=\sum_{g=1}^{N_{x}} \sum_{h=1}^{N_{y}} K_{g-e, h-f} \cdot p_{k j}(e, f)
$$

where $K_{g-e, h-f}$ is the influence coefficient of the deformation of element $(g, h)$ caused by contact pressure $p_{k j}(e, f)$ on the element $(e, f)$. For additional information on the influence coefficient, please refers to Ref. [27].

Contact pressure $p_{k j}(g, h)$ and mutual approach $\delta_{k j}$ are solved through the method described above. In addition, the average contact pressure $p_{\mathrm{akj}}$ on the tooth surfaces can be obtained and used to calculate the friction coefficient.

\subsection{Relative sliding velocity between the tooth surfaces}

Relative sliding velocity is determined by the misalignment and loaded deformation under the actual operating condition. The rotation angle $\varphi_{2 k j}\left(\varphi_{1 k j}\right)$ of the driven LG considering misalignment can be obtained from Eq. (9). The mutual approach $\delta_{k j}$ can cause an additional angular displacement $\Delta \theta_{21 k j}\left(\varphi_{1 k j}\right)=$ $\delta_{k j} \cdot \cos \alpha_{k j} / m_{2 \mathrm{c}}\left(\varphi_{1 k j}\right)$ along the circumferential direction of the driven LG, assuming that the driving LG is fixed. Then, the rotation angle of the driven LG changes as $\varphi_{2 k j}^{\prime}\left(\varphi_{1 k j}\right)=\varphi_{2 k j}\left(\varphi_{1 k j}\right)-\Delta \theta_{21 k j}\left(\varphi_{1 k j}\right)$. The transmission ratio at the meshing point $k j$ is expressed as $i_{12}\left(\varphi_{1 k j}\right)=\mathrm{d} \varphi_{1 k j} / \mathrm{d} \varphi_{2 k j}^{\prime}\left(\varphi_{1 k j}\right)$. If the angular velocity of the driving LG in $o_{1}-x_{1} y_{1} z_{1}$ is given as $\omega_{1}^{(1)}=$ $\left\{0,0, \omega_{1}\right\}$ then the angular velocity of the driven LG in $o_{2}-x_{2} y_{2} z_{2}$ is expressed as $\omega_{2}^{(2)}=\left\{0,0,-\omega_{1}\right\}$ $\left.i_{12}\left(\varphi_{1 k j}\right)\right\}$. The expressions of $\omega_{1}$ and $\omega_{2}$ in $o_{\mathrm{f}}-$ $x_{\mathrm{f}} y_{\mathrm{f}} z_{\mathrm{f}}$ are presented as Eq. (15).

$$
\left\{\begin{array}{l}
\boldsymbol{\omega}_{1}^{(\mathrm{f})}=\mathbf{L}_{\mathrm{f} 1} \cdot \boldsymbol{\omega}_{1}^{(1)} \\
\boldsymbol{\omega}_{2}^{(\mathrm{f})}=\mathbf{L}_{\mathrm{f} 2} \cdot \boldsymbol{\omega}_{2}^{(2)}
\end{array}\right.
$$

where $\mathbf{L}_{\mathrm{f} 1}$ and $\mathbf{L}_{\mathrm{f} 2}$ are the transmission matrices.

As shown in Fig. 1, the vectors from the point $o_{1}$ to the point $k j$ and from the point $o_{2}$ to the point $k j$, are presented as Eq. (16).

$$
\left\{\begin{array}{l}
\boldsymbol{R}_{1}^{(\mathrm{f})}\left(\varphi_{1 k j}\right)=\overrightarrow{o_{1} k j}=\overrightarrow{o_{\mathrm{f}} k j}-\overrightarrow{o_{\mathrm{f}} o_{1}}=\Sigma_{1}^{(\mathrm{f})}\left(\varphi_{1 k j}\right)-\{a+\delta a, 0, \delta b\} \\
\boldsymbol{R}_{2}^{(\mathrm{f})}\left(\varphi_{1 k j}\right)=\overrightarrow{o_{2} k j}=\overrightarrow{o_{\mathrm{f}} k j}=\Sigma_{1}^{(\mathrm{f})}\left(\varphi_{1 k j}\right)
\end{array}\right.
$$

Therefore, the relative sliding velocity between the tooth surfaces at the point $k j$ is presented as Eq. (17).

$$
\boldsymbol{v}_{12}^{(\mathrm{f})}\left(\varphi_{1 k j}\right)=\boldsymbol{\omega}_{1}^{(\mathrm{f})} \times \boldsymbol{R}_{1}^{(\mathrm{f})}\left(\varphi_{1 k j}\right)-\boldsymbol{\omega}_{2}^{(\mathrm{f})} \times \boldsymbol{R}_{2}^{(\mathrm{f})}\left(\varphi_{1 k j}\right)
$$

\section{Testing and fitting formula for the friction coefficient of POM LG pair}

In this section, a friction experiment is conducted to determine the friction coefficient of the POM LG pair under dry friction conditions. POM specimens in the shape of the ball and disk are prepared for the friction experiment to simulate the point-contact model of the LG pair. Several normal loads and relative sliding velocity levels are set according to the operating conditions of the plastic LG pair. The calculation formula for the friction coefficient of the POM LG pair under dry friction conditions is obtained by the measured friction coefficient data of the POM specimens.

\subsection{Preparation of specimens and experimental setup}

Several types of friction experiments, including ball-on-disk, ring-on-block, twin-disk, and pin-ondisk experiments [20, 28-30], can be conducted to determine the friction coefficient for different contact models under dry friction conditions. The ball-ondisk experiment can simulate the point-contact model of the LG pair. Thus, the ball-on-disk experiment was conducted to determine the friction coefficient of the POM specimens in this study. POM specimens in the shape of a ball and disk are shown in Fig. 5. The diameter of the POM ball specimen is $9.5 \mathrm{~mm}$, and that of the POM disk specimen is $46 \mathrm{~mm}$. All the specimens were cleaned with alcohol before the friction experiment.

The Universal Mechanical Tester (UMT Tribolab) was used in the ball-on-disk test, as shown in Fig. 6(a). It consists of a rotation motor, linear motor, fixtures of the specimens, load cell, normal load 


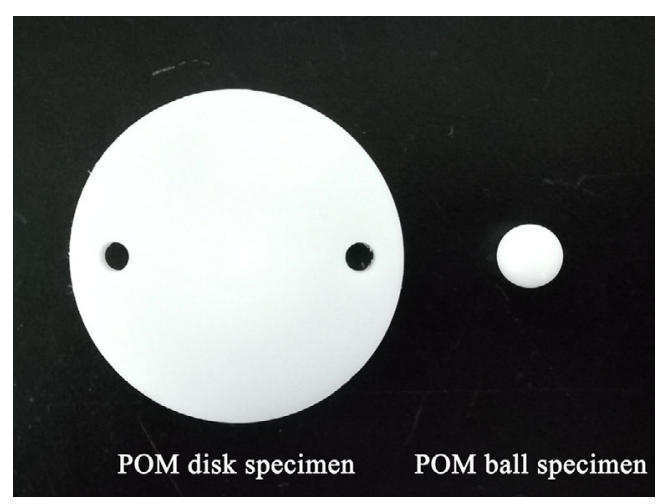

Fig. 5 POM ball and disk specimens.

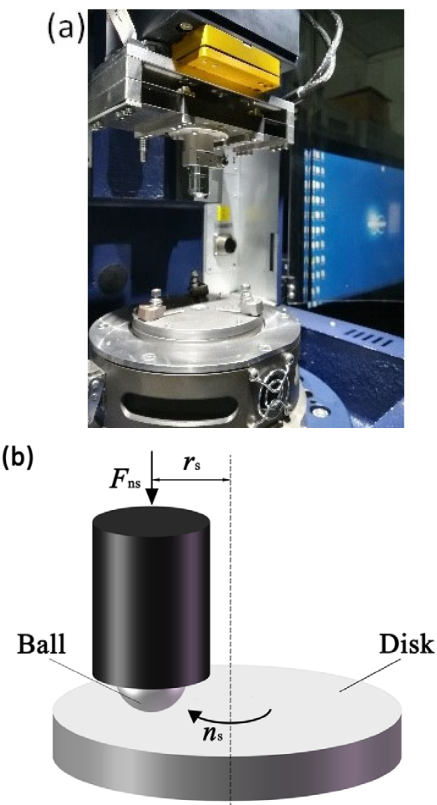

Fig. 6 UMT Tribolab and schematic diagram of the ball-ondisk experiment: (a) UMT Tribolab and (b) schematic diagram of the ball-on-disk experiment.

sensor, and frictional moment sensor. The schematic diagram of the ball-on-disk experiment is shown in Fig. 6(b). The POM ball specimen is fixed at the end of the fixture and the POM disk specimen below the ball specimen is connected to the rotation motor and rotates around its axis at a constant speed. The relationship between the rotational speed $n_{\mathrm{s}}$ of the rotation motor and the relative sliding velocity $v_{\mathrm{s}}$ of the POM specimens is as $v_{\mathrm{s}}=n_{\mathrm{s}} r_{\mathrm{s}} \pi / 30$, where $r_{\mathrm{s}}$ is the rotation radius adjusted by the linear motor. The load cell provides a constant normal load $F_{\text {ns }}$ for the POM specimens. The normal load sensor measures the real-time normal load. The frictional moment sensor measures the real-time frictional moment $T_{\mathrm{fs}}$ and transforms
$T_{\mathrm{fs}}$ into the frictional force $F_{\mathrm{fs}}$. Then, the real-time friction coefficient of the POM specimens is obtained according to $\mu_{\mathrm{s}}=F_{\mathrm{fs}} / F_{\mathrm{ns}}$.

\subsection{Experimental approach}

External environmental factors, such as temperature and humidity, were not considered in this study. Thus, the main factors affecting the friction coefficient are the load and relative sliding velocity [19]. The normal load and relative sliding velocity were selected as two variables in the ball-on-disk experiment. The ranges of these two factors were determined according to the operating conditions of plastic LG pairs.

Contact pressure may be large at the meshing points owing to the point-contact model of the LG pair. The upper limit of the maximum contact pressure of the POM specimens is set at approximately 80 $\mathrm{MPa}$ according to the compression strength of POM, i.e., the maximum average contact pressure is approximately $50 \mathrm{MPa}$. The maximum normal load is set at approximately $25 \mathrm{~N}$ according to the dimensions of the POM specimens. The relative sliding velocity between the tooth surfaces is influenced by the design parameters, misalignment, and loaded deformation of the LG pair. As the sliding rates of PLGP are equal to zero under ideal conditions, and the rotational speeds and loads of plastic gear pair are small, the relative sliding velocity of the plastic LG pair should be relatively low, despite the misalignment and loaded deformation. The maximum relative sliding velocity was set as 2 $\mathrm{mm} / \mathrm{s}$. When $r_{\mathrm{s}}$ was set as $2 \mathrm{~mm}$, the maximum rotational speed was approximately $9.55 \mathrm{rpm}$.

The normal load levels were selected as $F_{\text {ns }}=$ $1.25,2.5,5,7.5,10,12.5,15,17.5,20$, and $22.5 \mathrm{~N}$. The rotational speeds were selected as $n_{\mathrm{s}}=2.39$, $4.77,9.55 \mathrm{rpm}$. Then the experiment is conducted under the conditions of dry friction, room temperature, and atmospheric humidity. All the tests were conducted for over $1 \mathrm{~h}$ to ensure that a stable friction coefficient can be obtained; each test was repeated three times.

\subsection{Experimental results and calculation formula for the friction coefficient}

As shown in Fig. 7, when the normal load is 


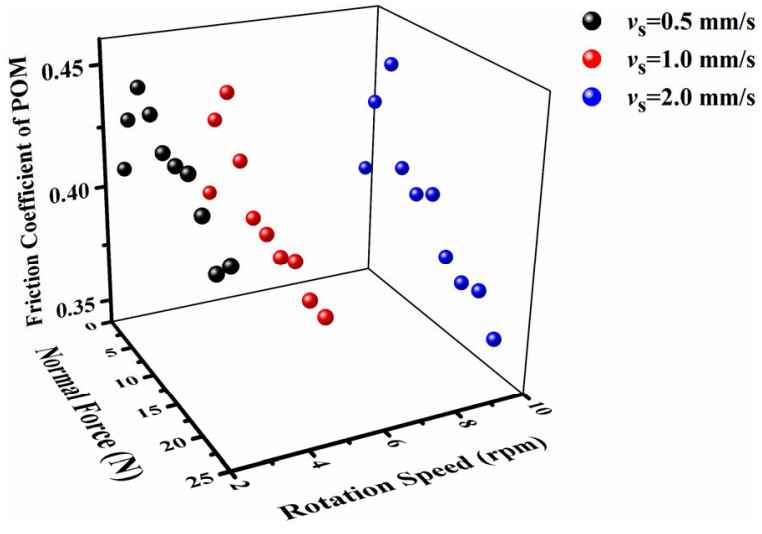

Fig. 7 Friction coefficient of the POM specimens.

$1.25-22.5 \mathrm{~N}$, and the rotational speed is $2.39-9.55$ $\mathrm{rpm}$, i.e., when the average contact pressure is approximately $20-50 \mathrm{MPa}$, and the relative sliding velocity is $0.5-2 \mathrm{~mm} / \mathrm{s}$, the measured friction coefficient $\mu_{\mathrm{s}}$ of the POM specimens varies between 0.35 and 0.45 . The maximum $\mu_{\mathrm{s}}$ was measured under a normal load of $5 \mathrm{~N}$ at a rotational speed of $2.39 \mathrm{rpm}$. The minimum $\mu_{\mathrm{s}}$ was measured under a normal load of $22.5 \mathrm{~N}$ at a rotational speed of $9.55 \mathrm{rpm}$. Under the studied loading conditions, $\mu_{\mathrm{s}}$ first increased and then decreased with increasing normal load. Specifically, $\mu_{\mathrm{s}}$ increases when the normal load is 1.25-5 N and decreases when the normal load is $5-22.5 \mathrm{~N}$. Under the studied relative sliding velocity conditions, $\mu_{\mathrm{s}}$ decreases with increasing relative sliding velocity.

The friction coefficient of POM against steel varies from approximately 0.2 to 0.4 when the contact pressure is $5-15 \mathrm{MPa}$, and the relative sliding velocity is $50-900 \mathrm{~mm} / \mathrm{s}$ [19]. The friction coefficient of POM against POM using PTFE lubricant varies from approximately 0.03 to 0.7 when the load is $15-450 \mathrm{~N}$, and the relative sliding velocity is $50-2,700 \mathrm{~mm} / \mathrm{s}$ [20]. In short, the friction coefficient of POM is influenced by the operating conditions, such as load, relative sliding velocity, and lubrication conditions.

An approximate functional relation between the friction coefficient and the average contact pressure and relative sliding velocity of the POM specimens was obtained by fitting the measured friction coefficient data. First, the average contact pressure $p_{\text {as }}$ and relative sliding velocity $v_{\mathrm{s}}$ were calculated according to the normal load $F_{n s}$ and rotational speed $n_{\mathrm{s}}$, respectively. Then, some empirical formulas were used to fit the measured friction coefficient data. The forms of these empirical formulas are shown as Eq. (18):

$$
\begin{aligned}
\mu_{\mathrm{s}}= & a_{30} \cdot p_{\mathrm{as}}^{3}+a_{21} \cdot p_{\mathrm{as}}^{2} \cdot v_{\mathrm{s}}+a_{12} \cdot p_{\mathrm{as}} \cdot v_{\mathrm{s}}^{2}+a_{20} \cdot p_{\mathrm{as}}^{2} \\
& +a_{11} \cdot p_{\mathrm{as}} \cdot v_{\mathrm{s}}+a_{02} \cdot v_{\mathrm{s}}^{2}+a_{10} \cdot p_{\mathrm{as}}+a_{01} \cdot v_{\mathrm{s}}+a_{00} \\
\mu_{\mathrm{s}}= & c \cdot e^{a \cdot p_{\mathrm{as}}} \cdot e^{b \cdot v_{\mathrm{s}}}+d \\
\mu_{\mathrm{s}}= & c \cdot \frac{p_{\mathrm{as}}^{a}}{v_{\mathrm{s}}^{b}}+d
\end{aligned}
$$

where $p_{\text {as }}(\mathrm{MPa})$ and $v_{\mathrm{s}}(\mathrm{mm} / \mathrm{s})$ are the average contact pressure and relative sliding velocity of the POM specimens, respectively.

The measured friction coefficient data were fitted using the MATLAB curving fitting tool, and the fitting formulas were obtained as Eq. (19):

$$
\begin{aligned}
\mu_{\mathrm{s}}= & (0.000009846) \cdot p_{\mathrm{as}}^{3}+(-0.00001378) \cdot p_{\mathrm{as}}^{2} \cdot v_{\mathrm{s}} \\
& +(0.0001391) \cdot p_{\mathrm{as}} \cdot v_{\mathrm{s}}^{2}+(-0.001175) \cdot p_{\mathrm{as}}^{2} \\
& +(-0.00004095) \cdot p_{\mathrm{as}} \cdot v_{\mathrm{s}}+(0.02061) \cdot v_{\mathrm{s}}^{2} \\
& +(0.04439) \cdot p_{\mathrm{as}}+(-0.06297) \cdot v_{\mathrm{s}}+(-0.05588) \\
\mu_{\mathrm{s}}= & (-0.0003745) \cdot e^{0.07626 \cdot p_{\mathrm{as}}} \cdot e^{0.6726 \cdot v_{\mathrm{s}}}+0.4303 \\
\mu_{\mathrm{s}} & =\left(-3.406 \times 10^{-8}\right) \cdot \frac{p_{\text {as }}{ }^{3.508}}{v_{\mathrm{s}}^{-0.6193}}+0.4230
\end{aligned}
$$

Goodness-of-fit was evaluated by the coefficient of determination and root-mean-squared error. As shown in Table 1, Eq. (19a) has the largest coefficient of determination and the smallest root-mean-squared error, i.e., Eq. (19a) is the most appropriate to describe the measured friction coefficient data. As shown in Fig. 8, the measured friction coefficient data are indicated by the dot-dash curves, and the calculated friction coefficient data by Eq. (19a) are indicated by the solid curves. It can be seen that the calculated result shows good agreement with the measured result.

Table 1 Coefficients of determination and root-mean-squared errors of the fitting formulas.

\begin{tabular}{ccc}
\hline $\begin{array}{c}\text { Fitting } \\
\text { formula }\end{array}$ & $\begin{array}{c}\text { coefficient of } \\
\text { determination }\end{array}$ & $\begin{array}{c}\text { Root-mean- } \\
\text { squared error }\end{array}$ \\
\hline Eq. (19a) & 0.919 & 0.008 \\
Eq. (19b) & 0.586 & 0.016 \\
Eq. (19c) & 0.553 & 0.017 \\
\hline
\end{tabular}




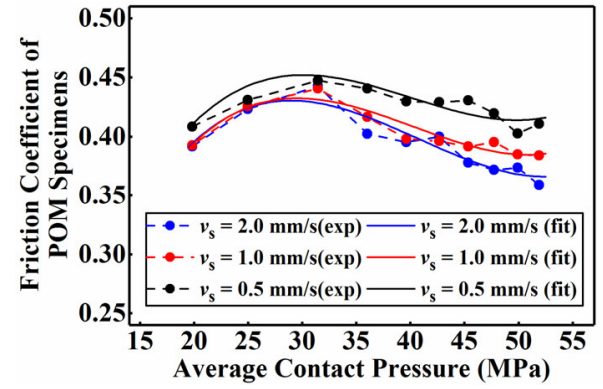

Fig. 8 Comparison between calculated and measured friction coefficient data.

By replacing $p_{\text {as }}$ and $v_{\mathrm{s}}$ in Eq. (19a) with the average contact pressure $p_{a k j}$ and relative sliding velocity $v_{12}\left(\varphi_{1 k j}\right)$ of the LG pair, respectively, the calculation formula for the friction coefficient of POM LG pair under dry friction conditions is obtained as Eq. (20):

$$
\begin{aligned}
\mu\left(\varphi_{1 k j}\right)= & (0.000009846) \cdot p_{\mathrm{akj}}^{3} \\
& +(-0.00001378) \cdot p_{\mathrm{akj}}^{2} \cdot \boldsymbol{v}_{12}\left(\varphi_{1 k j}\right) \\
& +(0.0001391) \cdot p_{\mathrm{akj}} \cdot \boldsymbol{v}_{12}^{2}\left(\varphi_{1 k j}\right) \\
& +(-0.001175) \cdot p_{\mathrm{akj}}^{2}+(-0.00004095) \cdot p_{\mathrm{akj}} \cdot \boldsymbol{v}_{12}\left(\varphi_{1 k j}\right) \\
& +(0.02061) \cdot \boldsymbol{v}_{12}^{2}\left(\varphi_{1 k j}\right)+(0.04439) \cdot p_{\mathrm{akj}} \\
& +(-0.06297) \cdot \boldsymbol{v}_{12}\left(\varphi_{1 k j}\right)+(-0.05588)
\end{aligned}
$$

where $p_{\text {akj }}(\mathrm{MPa})$ and $\boldsymbol{v}_{12}\left(\varphi_{1 k j}\right)(\mathrm{mm} / \mathrm{s})$ are the average contact pressure and relative sliding velocity at the point $k j$, respectively.

It should be noted that Eq. (20) can be applied to calculate the friction coefficient of the POM LG pair under dry friction conditions within the operating conditions in this study. However, the extrapolation of Eq. (20) to its application is not recommended as this is beyond the scope of the operating conditions.

\section{Meshing efficiency of POM LG pair}

Taking POM PLGP as an example, the meshing efficiency of the plastic LG pair was studied by comparing the calculated and experimental results of the POM PLGP specimens.

\subsection{Calculation method and formula for meshing efficiency}

The calculation method for the meshing efficiency of the LG pair is shown as the flowchart in Fig. 9. A meshing period of tooth pair $j$ was divided evenly into $K$ meshing positions, i.e., the range of rotation angle $\varphi_{1 j}$ was discretized evenly as $\varphi_{11 j}, \ldots, \varphi_{1 k j}, \ldots, \varphi_{1 K j}$. Then, by giving the design parameters, input rotational speed, and output torque of the LG pair, the normal force $F_{\mathrm{n} 2}\left(\varphi_{1 k j}\right)$, average contact pressure $p_{a k j}$, and relative sliding velocity $v_{12}\left(\varphi_{1 k j}\right)$ at the meshing point $k j$ of the tooth pair $j$ were obtained. The friction coefficient $\mu\left(\varphi_{1 k j}\right)$ was calculated by substituting $p_{a k j}$ and $\boldsymbol{v}_{12}\left(\varphi_{1 k j}\right)$ into Eq. (20). Assuming that there are $J$ pairs of tooth meshing simultaneously, the expression of instantaneous frictional power losses $P_{\text {ins }}$ of the LG pair is presented as Eq. (21):

$$
P_{\text {ins }}=\sum_{j=1}^{J} \mu\left(\varphi_{1 k j}\right) \cdot F_{\mathrm{n} 2}\left(\varphi_{1 k j}\right) \cdot v_{12}\left(\varphi_{1 k j}\right)
$$

The instantaneous meshing efficiency $\eta_{\text {ins }}$ of the LG pair is presented as Eq. (22):

$$
\eta_{\text {ins }}=1-\frac{P_{\text {ins }}}{T_{2} \cdot \omega_{2}+P_{\text {ins }}}
$$

Assuming that the meshing process of each tooth pair is identical, the average meshing efficiency was obtained by superimposing the instantaneous meshing efficiency for all discrete meshing positions and then calculating the average value for a meshing period of tooth pair $j$. The calculation formula for the average meshing efficiency $\eta_{\text {cal }}$ of the LG pair is presented as Eq. (23):

$$
\eta_{\text {cal }}=\frac{1}{K} \sum_{k=1}^{K} \eta_{\text {ins }}
$$

\subsection{Calculation examples and results}

The parameters of the POM PLGP specimens are listed in Table 2. Computer numerical control (CNC) form milling of LG [31] is a commonly used manufacturing method that was adopted to manufacture the POM PLGP specimens, as shown in Fig. 10 The test results of misalignment as well as the input speeds and output torques of the POM PLGP specimens are summarized in Table 3.

For a meshing period from meshing start to meshing end of a tooth pair, the range of $\varphi_{1 j}$ is $[0, \pi / 2]$, which is evenly discretized as $\varphi_{1 k j}=$ 


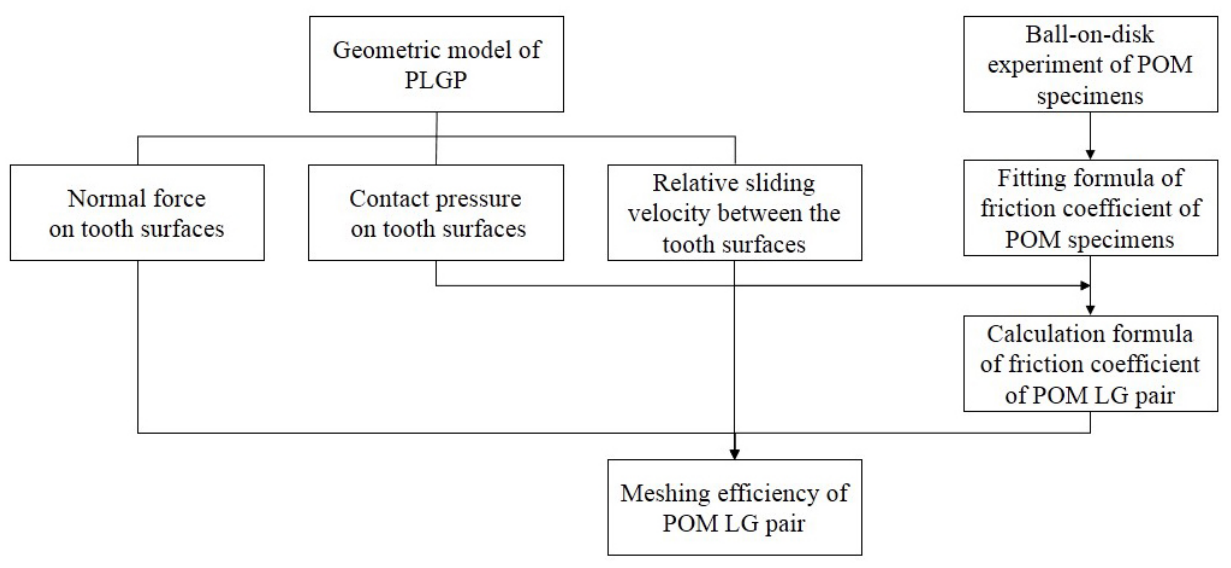

Fig. 9 Flowchart of meshing efficiency calculation method.
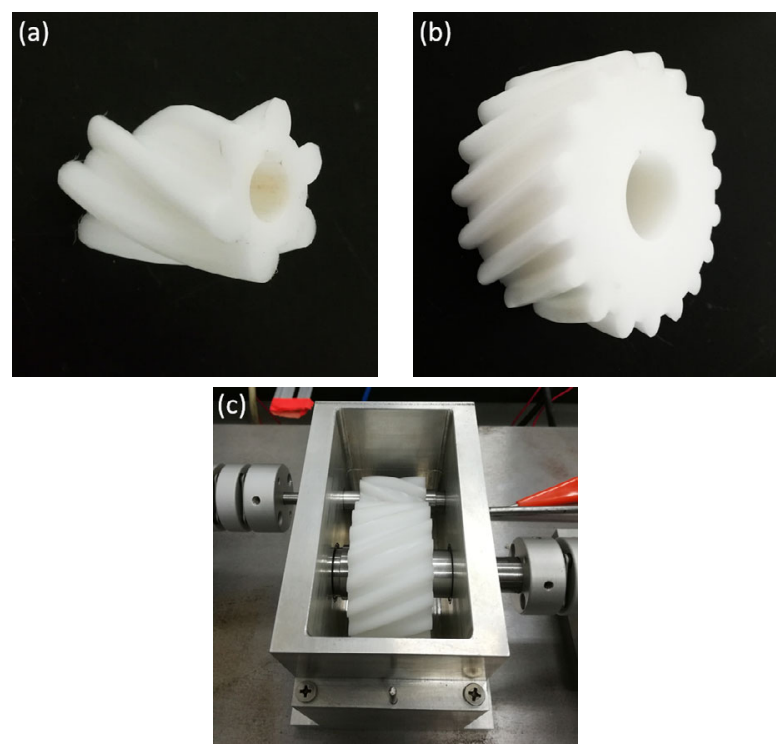

Fig. 10 POM PLGP specimens: (a) Driving LG (pinion), (b) Driven LG (gear), and (c) POM PLGP in a gearbox.

$(k-1) \pi / 18(k=1, \ldots, 10)$. Then $F_{\mathrm{n} 2}\left(\varphi_{1 k j}\right), p_{\mathrm{akj}}, \boldsymbol{v}_{12}\left(\varphi_{1 k j}\right)$, $\mu\left(\varphi_{1 k j}\right)$, and $\eta_{\text {cal }}$ of the POM LG specimens were calculated according to the method described above.

Table 2 Parameters of POM PLGP.

\begin{tabular}{lcc}
\hline Parameters of POM PLGP & Driving LG & Driven LG \\
\hline$\left(m_{i}, n_{i}\right)(\mathrm{mm})$ & $(10,20)$ & $(30,-60)$ \\
$R_{i}(\mathrm{~mm})$ & 4 & 4 \\
$\phi_{z i}(\mathrm{rad})$ & $\pi / 6$ & $5 \pi / 6$ \\
Tooth number, $z_{i}$ & 6 & 18 \\
$\left(t_{\mathrm{si}}, t_{\mathrm{e} i}\right)$ & $(-\pi,-\pi / 2)$ & $(0,-\pi / 6)$ \\
$i_{12}$ & \multicolumn{3}{c}{1.5} \\
Contact ratio & \multicolumn{2}{c}{2750} \\
Young's modulus $(\mathrm{MPa})$ & \multicolumn{3}{c}{0.37} \\
Poisson's ratio & \multicolumn{3}{c}{} \\
\hline
\end{tabular}

Table 3 Misalignments and operating conditions of POM PLGP.

\begin{tabular}{cc}
\hline \multicolumn{2}{c}{ Misalignments of POM PLGP } \\
\hline$\delta a(\mathrm{~mm})$ & -0.0200 \\
$\delta b(\mathrm{~mm})$ & 0.0000 \\
$\gamma_{\mathrm{h}}(\mathrm{rad})$ & -0.0001 \\
$\gamma_{\mathrm{v}}(\mathrm{rad})$ & 0.0001 \\
\hline Input angular velocity $\omega_{1}\left(\mathrm{rad} \cdot \mathrm{s}^{-1}\right)$ & $26.18,31.42,36.65$ \\
$\left(\right.$ Input rotational speed $\left.n_{1}(\mathrm{rpm})\right)$ & $(250,300,350)$ \\
Output torques $T_{2}(\mathrm{~N} \cdot \mathrm{mm})$ & $100,200,300,400,500$ \\
\hline
\end{tabular}

The friction coefficient $\mu\left(\varphi_{1 k j}\right)$ varied with the load and relative sliding velocity at different meshing positions during the meshing process. As shown in Fig. 11, $\varphi_{1 j} \in[\pi / 6, \pi / 3]$ is the case of single-tooth meshing and $\varphi_{1 j} \in[0, \pi / 6]$ and $\varphi_{1 j} \in$ $[\pi / 3, \pi / 2]$ are the cases of double-tooth meshing. $\mu\left(\varphi_{1 k j}\right)$ keeps constant in both the cases of singletooth and double-tooth meshing.

As shown in Fig. 11(a), when the output torque $T_{2}$ is $300 \mathrm{~N} \cdot \mathrm{mm}, \mu\left(\varphi_{1 k j}\right)$ decreased with increasing input rotational speed, and the calculated results under other output torques are similar. As shown in Fig. 11(b), when the input rotational speed $n_{1}$ is $300 \mathrm{rpm}, \mu\left(\varphi_{1 k j}\right)$ first increased with increasing output torque when the output torque $T_{2}$ is 100-300 N.mm, and then it slightly increased to the peak value 0.45 when $T_{2}$ is $300-500 \mathrm{~N} \cdot \mathrm{mm}$. After $T_{2}$ reaches $600 \mathrm{~N} \cdot \mathrm{mm}, \mu\left(\varphi_{1 k j}\right)$ began to decrease slightly. The calculated results under other input rotational speeds are similar. 

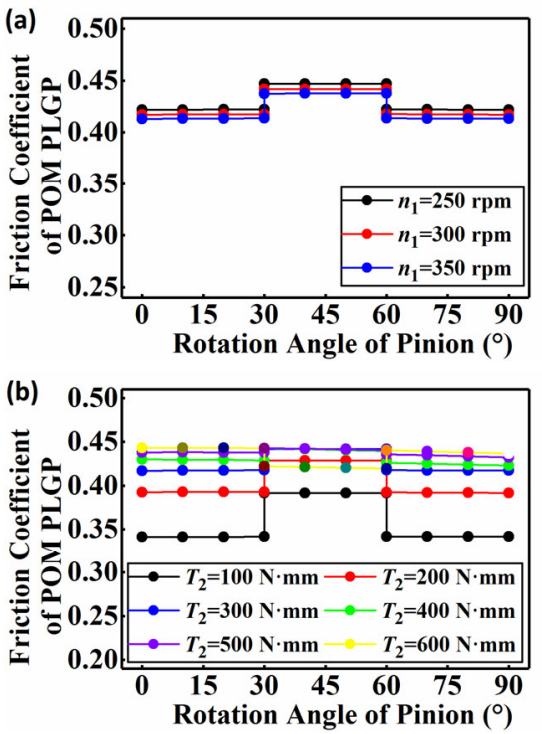

Fig. 11 Friction coefficient during the meshing process: (a) $T_{2}=300 \mathrm{~N} \cdot \mathrm{mm}$ and (b) $n_{1}=300 \mathrm{rpm}$.

As shown in Fig. 12, the calculated meshing efficiency $\eta_{\text {cal }}$ under the same $T_{2}$ increased slightly with increasing $n_{1}$ when $n_{1}$ is $250-350 \mathrm{rpm}$. $\eta_{\text {cal }}$ under the same $n_{1}$ first decreased and then increased with increasing $T_{2}$ when $T_{2}$ is $100-600 \mathrm{~N} \cdot \mathrm{mm}$. $\eta_{\text {cal }}$ varied with the output torque and input rotational speed similar to the variation of friction coefficient. As the meshing efficiency under a certain operating condition is influenced by the load, rotational speed, and friction coefficient, fluctuations of the calculated results are inevitable, but since the frictional losses are small under the operating conditions, the fluctuation is very slight, and the average calculated meshing efficiency is around $99.88 \%$.

\subsection{Meshing efficiency experiment}

\subsubsection{Experimental setup and conditions}

A homemade gear meshing efficiency test rig was developed to measure the meshing efficiency of the POM PLGP specimens. As shown in Fig. 13, the test rig consists of gearbox 1 , rotational speed, and torque sensors 2 and 6 , servo motor 3 , powder brake 4 , and flexible couplings 5 . Servo motor 3 provides sufficient input torque and constant input rotational speed for gearbox 1 . The powder brake 4 applies constant output torque onto gearbox 1 . The rotational speed and torque sensor 2 located between gearbox 1 and servo motor 3 collects the

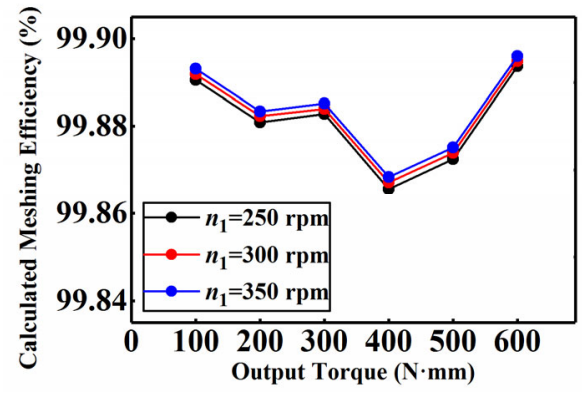

Fig. 12 Calculated results of average meshing efficiency.

real-time input rotational speed and torque data of gearbox 1 . The rotational speed and torque sensor 6 located between gearbox 1 and powder brake 4 collects the real-time output rotational speed and torque data of gearbox 1 .

Input rotational speed levels are set as 250, 300, and $350 \mathrm{rpm}$. Under each input rotational speed condition, the output torque applied by powder brake 4 increased gradually from 0 to approximately $600 \mathrm{~N} \cdot \mathrm{mm}$.

\subsubsection{Experimental results and analysis}

The total power losses of the gearbox are expressed as Eq. (24):

$$
P_{\text {total }}=T_{\text {in }} \cdot \omega_{\text {in }}-T_{\text {out }} \cdot \omega_{\text {out }}=P_{\text {load }}+P_{\text {spin }}
$$

where $T_{\text {in }}$ and $T_{\text {out }}$ are the measured input and output torques; and $\omega_{\text {in }}$ and $\omega_{\text {out }}$ are the measured input and output angular velocities, respectively.

Total power losses $P_{\text {total }}$ consist of the loaddependent power losses $P_{\text {load }}$ and load-independent power losses $P_{\text {spin }}$. $P_{\text {spin }}$ was measured under the non-loading condition, and the measured results

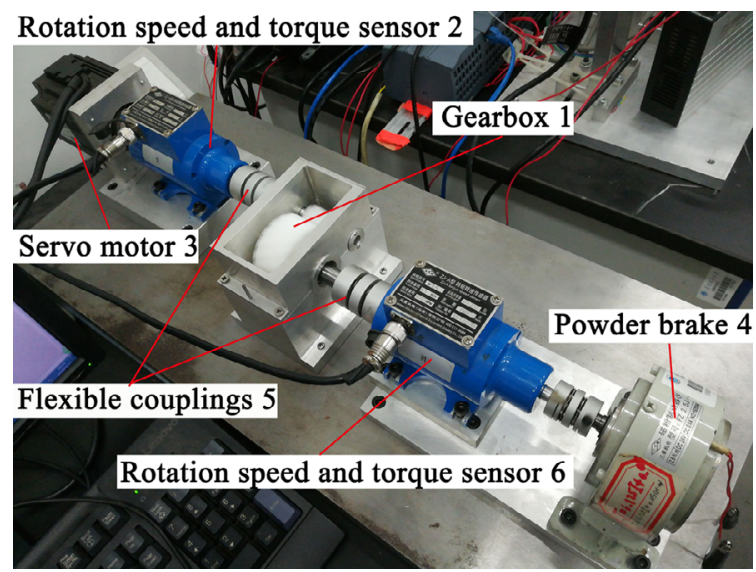

Fig. 13 Line gear meshing efficiency test rig. 
under the loading condition are the sum of $P_{\text {load }}$ and $P_{\text {spin }}$. Thus, after conducting the meshing efficiency experiment under both the non-loading and loading conditions, $P_{\text {load }}$ was obtained as $P_{\text {load }}=P_{\text {total }}-P_{\text {spin }}$. $P_{\text {load }}$ consists of various power losses from the POM PLGP specimens, rolling bearings, and flexible couplings. Power losses of the rolling bearings were calculated according to the product manual and the transmission efficiency of the flexible couplings was approximately $99.5 \%$. The measured power losses from the POM PLGP specimens is calculated by Eq. (25):

$$
\begin{aligned}
P_{\text {mesh }} & =P_{\text {load }}-P_{\text {bearing }}-P_{\text {coupling }} \\
& =T_{\text {in }} \cdot \omega_{\text {in }}-T_{\text {out }} \cdot \omega_{\text {out }}-P_{\text {spin }}-P_{\text {bearing }}-P_{\text {coupling }}
\end{aligned}
$$

Then the measured meshing efficiency of the POM PLGP specimens is calculated by Eq. (26):

$$
\eta_{\text {mesh }}=1-\frac{P_{\text {mesh }}}{T_{\text {out }} \cdot \omega_{\text {out }}+P_{\text {mesh }}}
$$

The calculated and measured meshing efficiency under different input rotational speed conditions are shown in Figs. 14(a)-14(c) respectively. Measured meshing efficiency is indicated by the dashed curves and the calculated meshing efficiency is indicated by the solid curves. Under all set rotational speed and loading conditions, the measured meshing efficiency values ranged between $99.5 \%$ and $100 \%$ and correspond with the calculated meshing efficiency values with maximal deviation of less than $1 \%$. This confirms the validity of the proposed calculation method for the friction coefficient and meshing efficiency of plastic LG pair under dry friction conditions. The fluctuation of the measured results and the deviations between measured and calculated results were attributed to the errors in data collection and processing, manufacturing errors of the POM
PLGP specimens, and rolling friction power losses, which were neglected in the calculation procedure.

\section{Discussion}

Metal gears cannot be used in some practical situations. For example, since the electromagnetic interference caused by metallic materials can deteriorate the communication quality, plastic gear pairs must be utilized in the RCU transmission system to adjust the tilt angle of the base station antenna instead of metal gear pairs. POM has the advantages of high strength, low hygroscopicity, good wear resistance, and is capable of adapting to complicated outdoor operating conditions. Therefore, POM gear pairs are commonly used in the current RCU transmission system.

Temperature is regarded as an important factor influencing the meshing efficiency of the POM gear pair. Frictional and hysteresis losses during the meshing process are the two sources causing temperature rise of the POM gear pair without considering of impact of ambient temperature, and temperature rise mainly generates from frictional losses since the latter is negligible [5, 32]. However, both the calculated and measured results of the meshing efficiency of the POM PLGP indicate that the frictional losses are extremely small. Thus, there is no significant temperature rise compared to other types of POM gear pairs during the low power meshing process. The meshing efficiency of POM involute gear pair is around 93\% when $n_{1}=300 \mathrm{rpm}$ and $T_{2}=1,000 \mathrm{~N} \cdot \mathrm{mm}$ [33], that of POM sine-curve gear pair is around $94 \%$ when $n_{1}=300 \mathrm{rpm}$ and $T_{2}=1,000 \mathrm{~N} \cdot \mathrm{mm}[33]$, but that of POM PLGP is higher than $99 \%$ when $n_{1}=300 \mathrm{rpm}$ and $T_{2}=500 \mathrm{~N} \cdot \mathrm{mm}$.
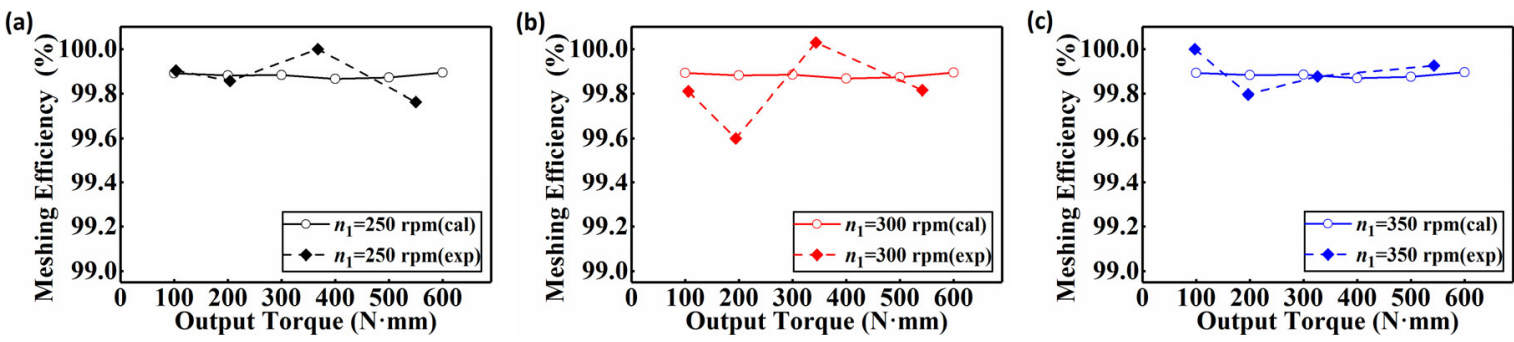

Fig. 14 Comparison between measured and calculated meshing efficiency. 
This paper focuses on the meshing efficiency of POM PLGP under normal use which mainly correlates to load, rotational speed, and misalignment. It should be noted that significant wear and deformation may occur on the tooth surfaces under a long-term operation that increases the relative sliding between the meshing surfaces, leading to frictional losses and temperature rise. Therefore, the effect of temperature must be considered in further studies of wear and fatigue failure of POM PLGP under long-term operation. For higher precision of the meshing efficiency calculation, the effects of the manufacturing errors of tooth surfaces must be considered in building the geometric and mechanical models of plastic LG pair.

\section{Conclusions}

Taking POM PLGP as an example, this paper proposed calculation methods and formulas for the friction coefficient and meshing efficiency of plastic LG pair under dry friction conditions. The main conclusions can be summarized as follows:

1) From the results of the ball-on-disk experiment, it was found that the friction coefficient of the POM specimens varied with the average contact pressure and relative sliding velocity, and ranged between 0.35 and 0.45 under the experimental conditions studied.

2) The calculated meshing efficiency is almost in coincidence with measured meshing efficiency, which validated the feasibility of the calculation methods and formulas for the friction coefficient and meshing efficiency of POM LG pair under dry friction conditions.

3) The study can serve as a reference for the calculation of the friction coefficient and meshing efficiency of plastic gear pairs under dry friction conditions. It also provides a basis for future studies of the wear calculation and lifetime prediction of plastic LG pairs.

\section{Acknowledgements}

The authors gratefully acknowledge the support from the National Natural Science Foundation of
China (No. 51575191) and 2019 Guangzhou Technology Project (No. 201904010368).

Open Access This article is licensed under a Creative Commons Attribution 4.0 International License, which permits use, sharing, adaptation, distribution and reproduction in any medium or format, as long as you give appropriate credit to the original author(s) and the source, provide a link to the Creative Commons licence, and indicate if changes were made.

The images or other third party material in this article are included in the article's Creative Commons licence, unless indicated otherwise in a credit line to the material. If material is not included in the article's Creative Commons licence and your intended use is not permitted by statutory regulation or exceeds the permitted use, you will need to obtain permission directly from the copyright holder.

To view a copy of this licence, visit http://creativecommons.org/licenses/by/4.0/.

\section{References}

[1] Takahashi M, Itagaki T, Takahashi H, Koide T, Kobori Y. Lifetime and meshing-teeth temperature of a crossed helical gear consisting of a plastic gear and a metal gear: In case of no-lubrication. $J$ Adv Mech Des, Syst, Manuf 11(6): 17-00385 (2017)

[2] Evans S M, Keogh P S. Efficiency and running temperature of a polymer-steel spur gear pair from slip/roll ratio fundamentals. Tribol Int 97: 379-389 (2016)

[3] Kirupasankar S, Gurunathan C, Gnanamoorthy R. Transmission efficiency of polyamide nanocomposite spur gears. Mater Des 39: 338-343 (2012)

[4] İmrek H. Performance improvement method for Nylon 6 spur gears. Tribol Int 42(3): 503-510 (2009)

[5] Singh P K, Siddhartha, Singh A K. An investigation on the thermal and wear behavior of polymer based spur gears. Tribol Int 118: 264-272 (2018)

[6] $\mathrm{Hu} \mathrm{Z} \mathrm{D,} \mathrm{Mao} \mathrm{K.} \mathrm{An} \mathrm{investigation} \mathrm{of} \mathrm{misalignment}$ effects on the performance of acetal gears. Tribol Int 116: 394-402 (2017)

[7] Mao K, Langlois P, Hu Z, Alharbi K, Xu X, Milson M, Li W, Hooke C J, Chetwynd D. The wear and thermal mechanical contact behaviour of machine cut polymer gears. Wear 332-333: 822-826 (2015)

[8] Walton D, Cropper A B, Weale D J, Meuleman P K. The 
efficiency and friction of plastic cylindrical gears Part 1: Influence of materials. Proc Inst Mech Eng, Part J: J Eng Tribol 216(2): 75-78 (2002)

[9] Kim S H, Shin M C, Byun J W, O K H, Chu C N. Efficiency prediction of worm gear with plastic worm wheel. Int J Precis Eng Manuf 13(2): 167-174 (2012)

[10] Chen Y Z. Line Gear. Beijing (China): Science Press, 2014.(in Chinese)

[11] Chen Y Z, Xing G Q, Peng X F. The space curve mesh equation and its kinematics experiment. In Proceedings of the 12th IFToMM World Congress, Besançon, France, 2007.

[12] Chen Y Z, Li Z, Xie X D, Lyu Y L. Design methodology for coplanar axes line gear with controllable sliding rate. Strojni ški Vestnik-J Mech Eng 64(6): 362-372 (2018)

[13] Ding J, Chen Y Z, Lv Y L, Song C H. Positionparameter selection criterion for a helix-curve meshingwheel mechanism based on sliding rates. Strojni $\check{s} k i$ Vestnik-J Mech Eng 60(9): 561-570 (2014)

[14] Xu H, Kahraman A. A frictional efficiency loss model for helical gears. In Proceedings of ASME 2005 International Design Engineering Technical Conferences and Computers and Information in Engineering Conference, Long Beach, California, USA, 2005: 897-908.

[15] Xu H, Kahraman A, Anderson N E, Maddock D G. Prediction of mechanical efficiency of parallel-axis gear pairs. J Mech Des 129(1): 58-68 (2007)

[16] Larson M G, Timpe S J. Effect of load and temperature on the tribological characteristics of a steel Pin on polyoxymethylene disk interface. J Tribol 139(5): 051603 (2017)

[17] Ziemianski K, Capanidis D. The mechanism of dry friction of polyoxymethylene against steel. Wear 82(3): 317-332 (1982)

[18] Ginzburg B M, Tochil'nikov D G, Lyashkov A I, Shiyan P A, Gaisin V M, Permyakov I V, Ponimatkin V P. Tribological behavior of polyoxymethylene in waterlubricated friction against steel. J Frict Wear 32(4): 246-250 (2011)

[19] Xiong X S, Hua L, Wan X J, Yang C, Xie C Y, He D. Experiment and simulation of friction coefficient of polyoxymethylene. Ind Lubr Tribol 70(2): 273-281 (2018)

[20] Miler D, Hoić M, Domitran Z, Žeželj D. Prediction of friction coefficient in dry-lubricated polyoxymethylene spur gear pairs. Mech Mach Theory 138: 205-222
(2019)

[21] Yada T. Review of gear efficiency equation and force treatment. JSME Int J, Series C 40(1): 1-8 (1997)

[22] Michlin Y, Myunster V. Determination of power losses in gear transmissions with rolling and sliding friction incorporated. Mech Mach Theory 37(2): 167-174 (2002)

[23] Marjanovic N, Ivkovic B, Blagojevic M, Stojanovic B. Experimental determination of friction coefficient at gear drives. J Balk Tribol Assoc 16(4): 517-526 (2010)

[24] Litvin F L, Tsay C B. Helical gears with circular arc teeth: Simulation of conditions of meshing and bearing contact. J Mech Trans Autom Des 107(4): 556-564 (1985)

[25] Polonsky I A, Keer L M. A numerical method for solving rough contact problems based on the multi-level multi-summation and conjugate gradient techniques. Wear 231(2): 206-219 (1999)

[26] Johnson K L. Contact Mechanics. Cambridge (UK): Cambridge University Press, 1985.

[27] $\mathrm{Wu} \mathrm{S} \mathrm{H,} \mathrm{Tsai} \mathrm{S} \mathrm{J.} \mathrm{Contact} \mathrm{stress} \mathrm{analysis} \mathrm{of} \mathrm{skew}$ conical involute gear drives in approximate line contact. Mech Mach Theory 44(9): 1658-1676 (2009)

[28] Amann T, Gatti F, Oberle N, Kailer A, Rühe J. Galvanically induced potentials to enable minimal tribochemical wear of stainless steel lubricated with sodium chloride and ionic liquid aqueous solution. Friction 6(2): 230-242 (2018)

[29] Mbarek M, Rhaiem S, Kharrat M, Dammak M. Experimental simulation of the friction, temperature, and wear distributions for polyamide-steel gear contact using twin-disc setup. Proc Inst Mech Eng, Part J: J Eng Tribol 230(9): 1127-1138 (2016)

[30] Jha P, Gautam R K, Tyagi R. Friction and wear behavior of $\mathrm{Cu}-4$ wt.\%Ni-TiC composites under dry sliding conditions. Friction 5(4): 437-446 (2017)

[31] Chen Y Z, Yao L. Study on a method of CNC form milling for the concave convex arc line gear. Int $J A d v$ Manuf Technol 99(9-12): 2327-2339 (2018)

[32] Koffi D, Gauvin R, Yelle H. Heat Generation in Thermoplastic Spur Gears. J Mech Trans and Automation 107(1): 31-36 (1985)

[33] Koide T, Yukawa T, Takami S, Ueda A, Moriwaki I, Tamura A, Hongu J. Tooth surface temperature and power transmission efficiency of plastic sine-curve gear. J Adv Mech Des Syst 11(6): 17-00451-17-00457 (2017) 


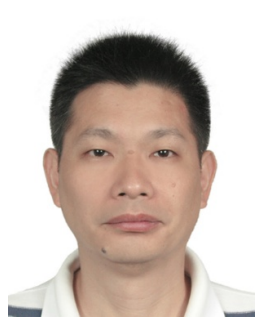

Yangzhi CHEN. He received his bachelor degree from Tianjin University, China, in 1986. He received his master and Ph.D. degrees from Zhejiang University, China, in 1992 and 1995, respectively.

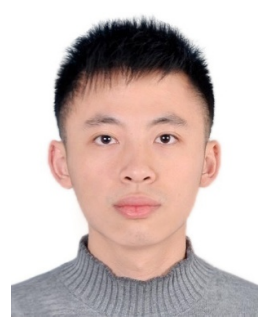

Yifan LIN. He received his bachelor degree from South China University of Technology, China, in 2014. Currently, he is a Ph.D. candidate
Currently, he is a professor and doctoral supervisor at the School of Mechanical and Automotive Engineering, South China University of Technology, China. His research areas cover line gear, tribology, and micro/nanotransmission.

in South China University of Technology, China. His research interests include line gear, friction, and wear of polymer gears. 